www.jmscr.igmpublication.org

Index Copernicus Value: 79.54

ISSN (e)-2347-176x ISSN (p) 2455-0450

crossrefDOI: https://dx.doi.org/10.18535/jmscr/v7i3.151

\title{
A Study on the Clinical Profile of Patients with Community Acquired Pneumonia Admitted to a Tertiary Care Centre in Rural South Kerala
}

\author{
Authors \\ Dr Suresh Raghavan ${ }^{1}$, Dr Arathi $\mathbf{N}^{2}$ \\ ${ }^{1}$ Professor, Department of Medicine, Government TD Medical College, Alappuzha \\ ${ }^{2}$ Assistant Professor, Department of Medicine, Government TD Medical College, Alappuzha \\ Corresponding Author \\ Dr Arathi N \\ Assistant Professor, Department of Medicine, Government TD Medical College, Vandanam PO \\ Alappuzha: 688005, India \\ Mobile: 9446724558, Email: arathi.n.iyer@gmail.com
}

\begin{abstract}
Background: Community Acquired pneumonia remains a major reason for admission to hospitals and a common cause of death in developing countries. Studies conducted in the developed countries forms the basis for various guidelines on this topic which is even more important problem in a country like India. Since the environmental and socioeconomic background of our area is different from those where the studies are carried out, there should be a difference in the pattern of Community Acquired Pneumonia in our area. This study is therefore carried out with the intention of identifying the clinoco-epidemiological profile of patients with Community Acquired Pneumonia in a hospital population in rural south kerala.

Objectives: To study the clinical profile of patients admitted with Community Acquired Pneumonia in a tertiary care centre and to assess the variability in presentations of Community Acquired Pneumonia in patients with Diabetes Mellitus compared to patients without Diabetes. Also to study the correlation of various presentations with the outcome.

Methods: This is an observational study which 150 patients satisfying the inclusion criteria were enrolled. The clinical features at the time of their presentation were noted. They were subjected to blood investigations which included routine investigations and chest radiograph, blood and/or sputum culture. A detailed analysis of the clinical features were studied with special reference to the difference in clinical presentations among diabetics and non diabetics. The final outcome of the patients were also studied and compared on the basis of their diabetic status.

Results: Out of the 150 patients, majority were males. The most common clinical manifestation was cough followed by fever. The clinical profile in diabetics were different in that fever was uncommon. Diabetics had a higher incidence of tachycardia and hypotension. Diabetics had higher serum creatinine at the time of presentation. 33\% had culture positivity. Mortality rate was higher in multilobar pneumonia. Presence of diabetes and CVA were assoiated with adverse outcomes. Diabetic patients had higher CURB 65 score indicationg the severity of the disease at the time of admission.

Conclusions: Clinical profile of patients with pneumonia differs according to their glycemic status.
\end{abstract}




\section{Background}

Community Acquired pneumonia remains a major reason for admission to hospitals and a common cause of death in developing countries. Most epidemiological data have been obtained from hospitalized patients with community acquired pneumonia. A few population based studies have been reported and little information is available on out patients treated by family physicians.

Studies conducted in the developed countries forms the basis for various guidelines on this topic which is even more important problem in a country like India. Since the environmental and socioeconomic background of our area is different from those where the studies are carried out, there should be a difference in the pattern of Community Acquired Pneumonia in our area.

This study is therefore carried out with the intention of identifying the clinocoepidemiological profile of patients with Community Acquired Pneumonia in a hospital population in rural south kerala.

\section{Aims and Objectives}

1. To study the clinical profile of patients admitted with Community Acquired Pneumonia in a tertiary care centre, with special reference to the age, gender, comorbid illness and microbiological pattern from the Sputum and Blood Cultures.

2. To assess the variability in presentations of Community Acquired Pneumonia in patients with Diabetes Mellitus compared to patients without Diabetes.

3. To study the correlation of various presentations with the outcome.

\section{Materials and Methods}

Study Population: 150 patients admitted with Community Acquired Pneumonia in the Departments of Internal Medicine and Respiratory Medicine a rural Tertiary care centre in South Kerala.

Study Design: Observational study

\section{Inclusion Criteria}

a. Age more than or equal to 13 years of both the sexes.

b. Presence of chest $X$ ray infiltrates suggestive of pneumonia

In the presence of any 2 of the following:

a. Fever $>38^{\circ} \mathrm{C}$ or hypothermia defined as temperature $<36^{\circ} \mathrm{C}$.

b. Cough

c. Sputum

d. Breathlessness

e. Hemoptysis

f. Pleuritic chest pain

g. Tachypnoea defined as respiratory rate more than 24 / minute

h. Auscultatory findings suggestive of Pneumonia: Crepitations, Broncial breath sounds, Pleural rub

\section{Exclusion Criteria}

a. Patients with diagnosed malignancies.

b. Duration of present illness more than 6 weeks.

c. Those who are not willing to give a consent.

\section{Methods}

Among the patients presenting to the outpatient department or emergency department of the institution who satisfied the inclusion criteria were enrolled in the study.

After history taking and physical examination the following investigations will be performed.

1. Blood Samples for: Complete Blood Counts, Erythrocyte Sedimentation Rate, Blood Urea, Serum Creatinine, Blood Sugars, 2 Samples for Blood Cultures.

2. Sputum sample for Culture and Sensitivity. One bottle will be provided to the patient for collection of early morning sample. 2 samples for examining Acid Fast Bacilli will also be obtained over the next 3 days.

3. Chest $\mathrm{X}$ ray PA view. 
After collection of blood and the sputum samples, the patient will be started on antibiotics according to our institutional protocol.

The patient is then followed up cclinically after 48 hours and then again on the $5^{\text {th }}$ day. If the patient has not improved at 72 hours, the antibiotics will be changed as per the protocol and re evaluated after 48 hours.

\section{Institutional Protocol for the choice of Antibiotics in a Patient with Community Acquired Pneumonia}

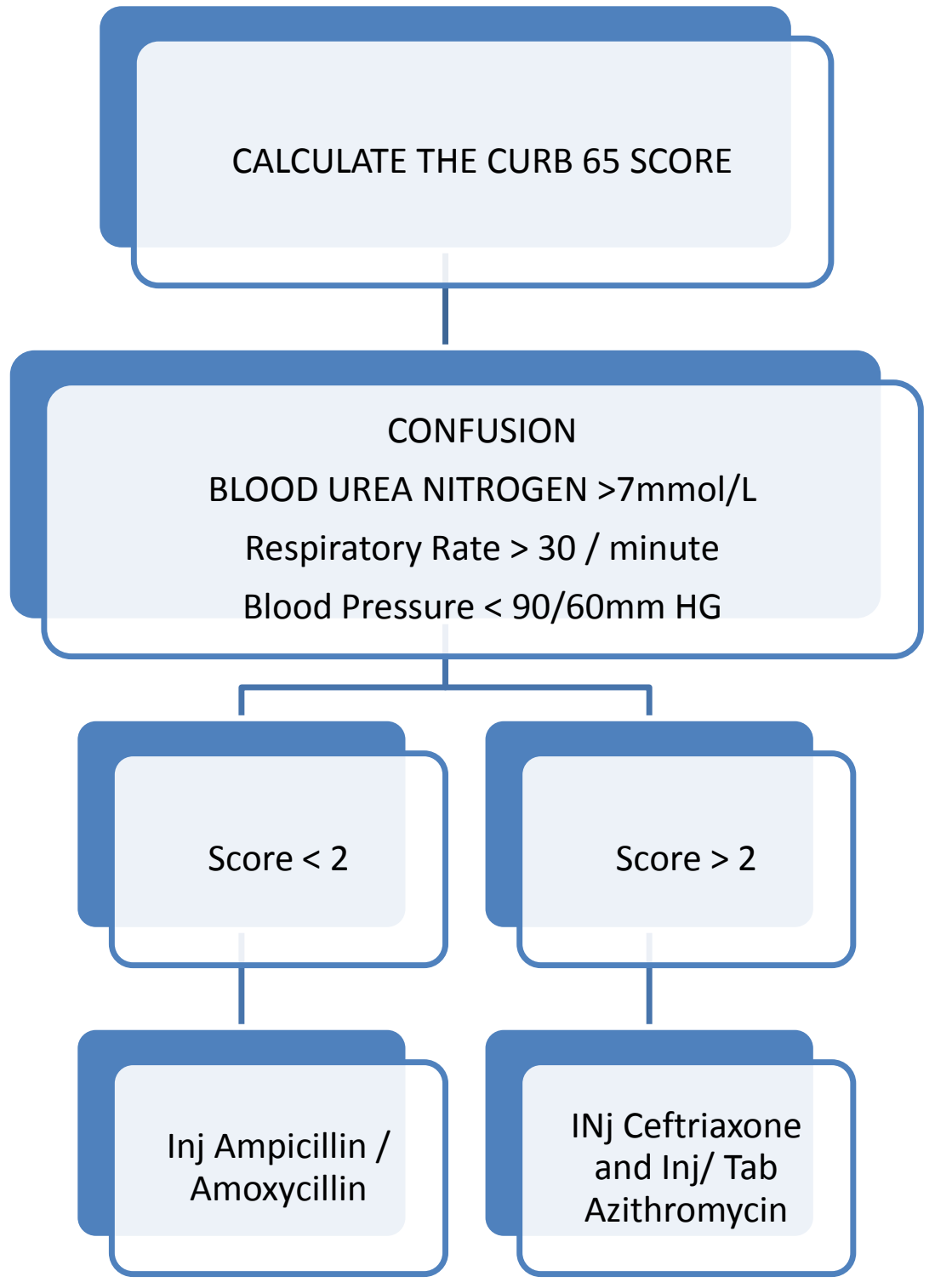

If the clinical condition is not improving after 72 hours, change the antibiotic according to the culture and sensitivity reports or switch to Injection Piperacillin plus Tazobactum.

If the patient is predisposed to aspiration( Alcohol intoxication, Cerebrovascular accident, Seizures), Injection Metronidazole will be added.

In documented cases of Bronchiectasis or patients who are on equivalent dose of prednisolone $>10$ mg / day for a period of more than 10 days, Injection Ciprofloxacin will be added

\section{Observations}

Of the 150 people enrolled, 97 (64.7\%) were males and 53(35.3\%) were females.

Age Distribution: Majority were in the age group more than 65 years $(34.6 \%)$ 
Figure 1: Age distribution of the population

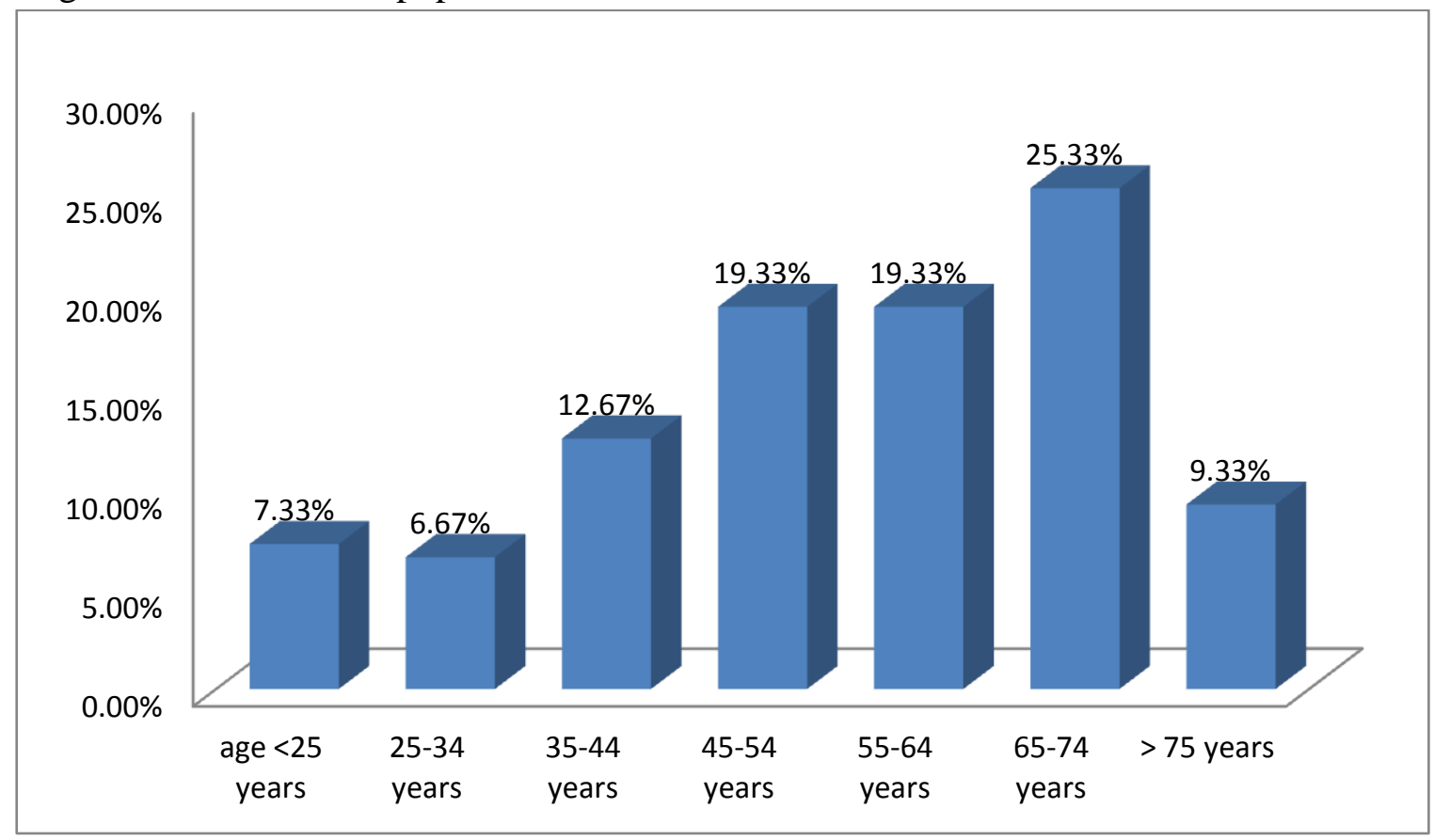

\section{Presenting Symptoms}

The most common presenting symptoms were cough $(92 \%)$ followed by fever $(88 \%)$ and sputum production $(85.3 \%)$. Other symptoms like myalgia, joint pains, loose stools and abdominal pain were present in a few patients.
Comparison of presenting symptoms in individuals with and without diabetes:

41 of the 150 patients had diabetes mellitus as a comorbid factor. The following results were obtained on comparing the symptoms in patients with and without diabetes.

Figure 2: Symptoms in patients with history of Diabetes Mellitus:

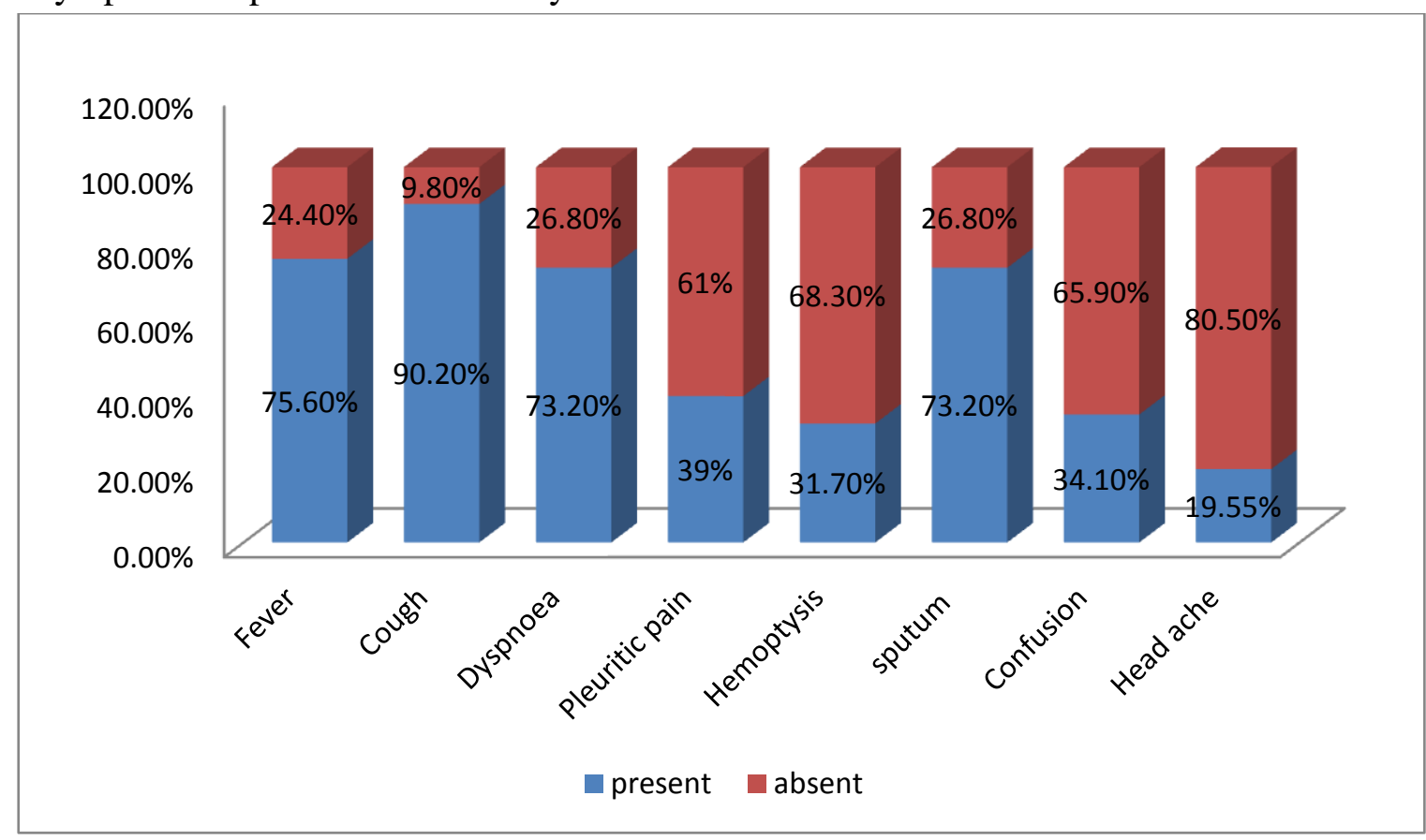


Figure 3: Symptoms in patients without history of Diabetes mellitus:

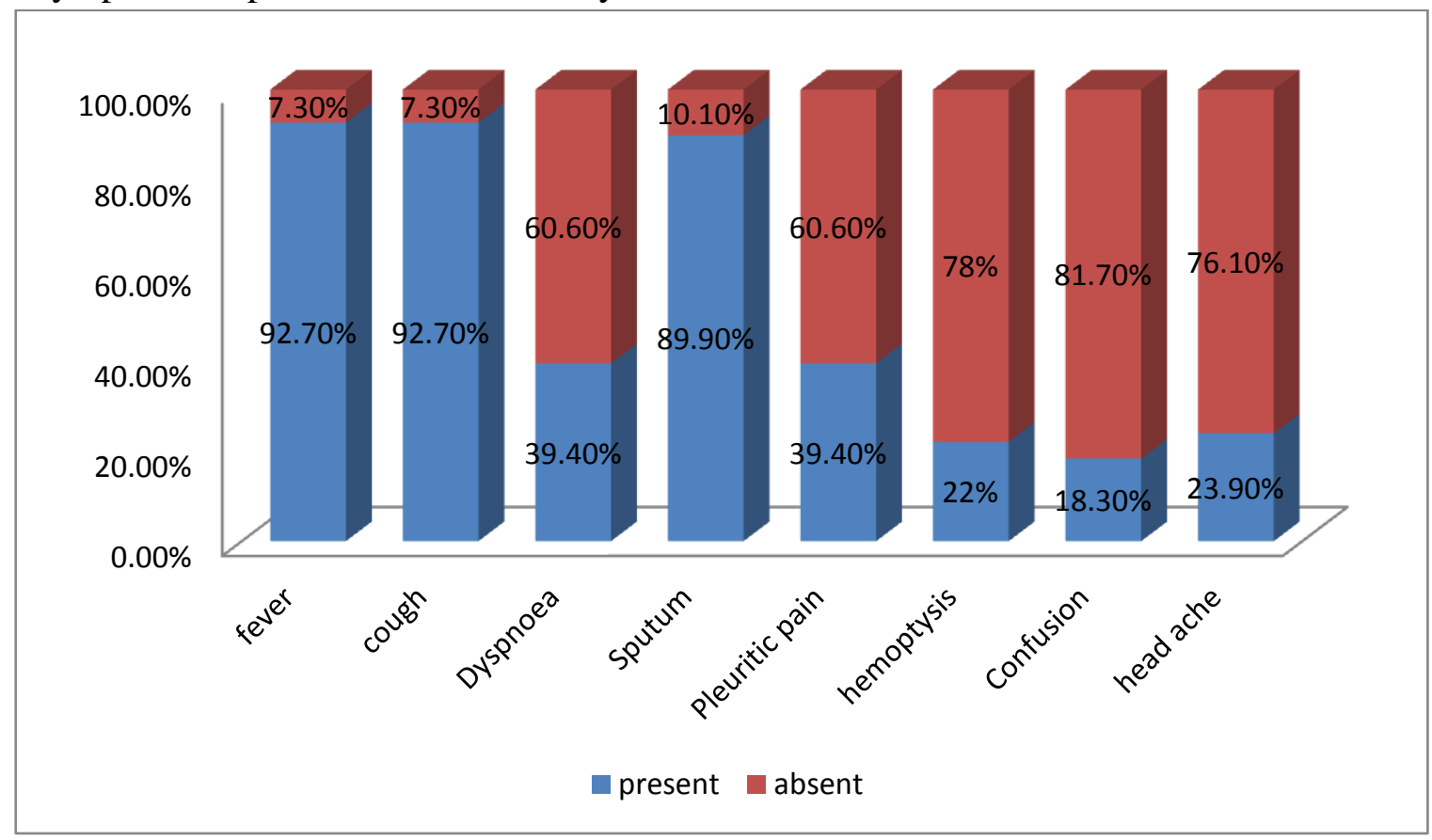

Compared to individuals without diabetes mellitus, fever was uncommon in diabetics, where as dyspnoea, sputum production and confusion were more seen in diabetics and all were statistically significant ( $\mathrm{p}$ value $<0.05$ )

In the study population, $9.3 \%$ had a systolic BP of $<90 \mathrm{~mm} \mathrm{Hg}, 14.7 \%$ had a diastolic Bp of $<60$ $\mathrm{mm} \mathrm{Hg}$. only $6 \%$ had a respiratory rate of $12-16$ breaths per minute, where as $48.7 \%$ had a respiratory rate between $16-30$ breaths per minute and $45.3 \%$ had a respiratory rate of $>30$ breaths per minute.

Crepitation were present in $85.7 \%$, bronchial breath sounds were seen in $39.3 \%$, Pleural rub in $28.7 \%$, rhonchi in $40 \%$ and cyanosis in $8 \%$.

\section{Comparison of Physical Signs in Patients with and without Diabetes Mellitus}

No significant difference was observed between the vital signs in diabetics and non diabetics. But, it was found that tachycardia and hypotension was more common in diabetics, with a significant $\mathrm{p}$ value $(<0.05)$.
The incidence of physical signs like presence of crepitations, bronchial breath sounds, pleural rub, cyanosis etc were not statistically significant between diabetics and non diabetics.

\section{Comparison of Laboratory Parameters among Diabetics and non Diabetics}

The mean serum creatinine in diabetics were $1.56 \mathrm{mg} \%$, where as the mean value in non diabetics were $1.1 \mathrm{mg} \%$ and there was a statistically significant association of higher serum creatinine levels in diabetics when compared to non diabetics ( $\mathrm{p}$ value <0.05). No such statistically significant difference could be established in case of other lab parameters like, blood urea, total count, differential count, ESR or hemoglobin levels. 


\section{JMSCR Vol||07||Issue||03||Page 875-883||March}

Table 1: Comparison of laboratory parameters in diabetics and non diabetics:

\begin{tabular}{|l|c|c|}
\hline \multirow{2}{*}{$\begin{array}{l}\text { LAB PARAMETER } \\
\text { (mean value) }\end{array}$} & \multicolumn{2}{|c|}{ DIABETES MELLITUS } \\
\cline { 2 - 3 } & PRESENT & ABSENT \\
\hline Blood Urea & 48.8 & 39.3 \\
\hline Creatinine & 1.56 & 1.1 \\
\hline Hemoglobin & 11.5 & 12.8 \\
\hline Total count & 9985 & 10367 \\
\hline Polymorphs & $74.15 \%$ & $80.04 \%$ \\
\hline Lymphocytes & $24.56 \%$ & $18.3 \%$ \\
\hline ESR & 59.66 & 55.55 \\
\hline
\end{tabular}

The most common lobe involved as per the chest $\mathrm{X}$ ray was the Right upper lobe(37\%). $22 \%$ had multi lobar involvement. $22 \%$ had associated pleural effusion.

Figure 4: Microbiology of the Culture Specimen:

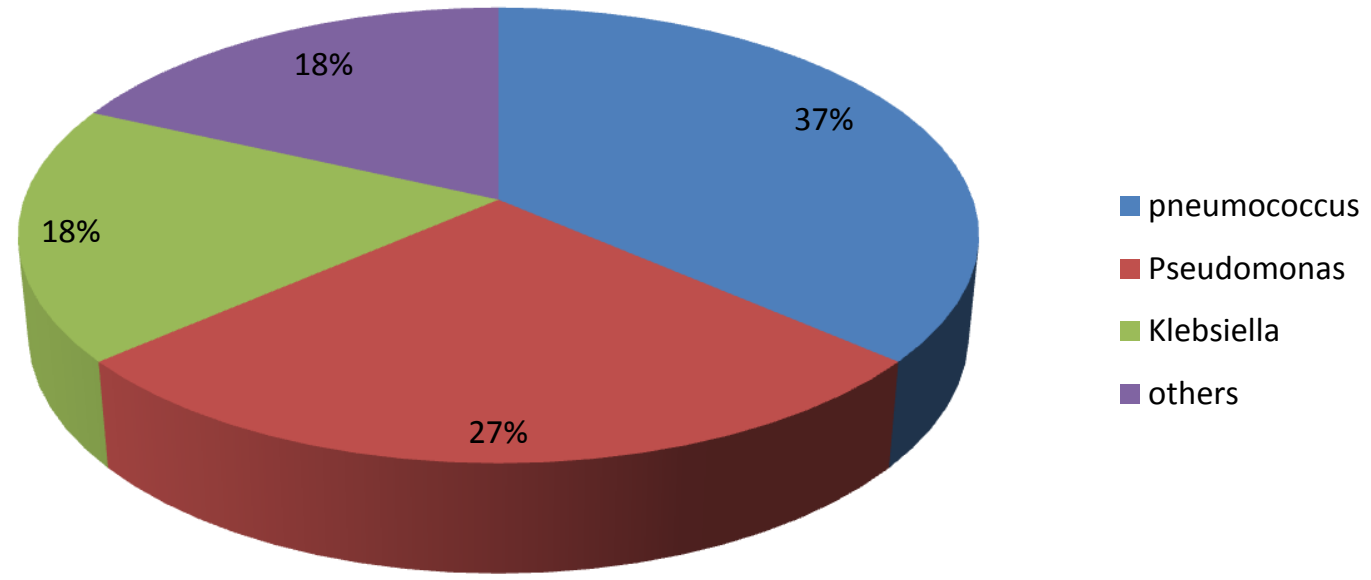

\section{Relation between the outcome in hospital and} various Variables

The outcome in hospital is defined as died or survived.

No significant difference were observed between the rtes of survival and the age or gender. Though, it was observed that the rate of deaths increased in elderly. 
Table 2: Outcome and symptoms

\begin{tabular}{|c|c|c|c|c|}
\hline \multirow{2}{*}{\multicolumn{2}{|c|}{ SYMPTOM }} & \multicolumn{2}{|c|}{ OUTCOME } & \multirow[t]{2}{*}{$\mathrm{P}$ value } \\
\hline & & DIED & SURVIVED & \\
\hline \multirow[b]{2}{*}{ Fever } & Present & $15.9 \%$ & $84.1 \%$ & \multirow[t]{2}{*}{0.07} \\
\hline & Absent & $33.3 \%$ & $66.7 \%$ & \\
\hline \multirow[b]{2}{*}{ Cough } & Present & $14.5 \%$ & $85.5 \%$ & \multirow[t]{2}{*}{$<0.001$} \\
\hline & Absent & $58.3 \%$ & $41.7 \%$ & \\
\hline \multirow{2}{*}{ Dyspnoea } & Present & $32.9 \%$ & $67.1 \%$ & \multirow[t]{2}{*}{$<0.001$} \\
\hline & Absent & $3.9 \%$ & $96.1 \%$ & \\
\hline \multirow[b]{2}{*}{ Sputum } & Present & $12.5 \%$ & $87.5 \%$ & \multirow[t]{2}{*}{$<0.001$} \\
\hline & Absent & $50 \%$ & $50 \%$ & \\
\hline \multirow[b]{2}{*}{ Pleuritic Pain } & Present & $10.2 \%$ & $89.8 \%$ & \multirow[t]{2}{*}{0.044} \\
\hline & Absent & $23.1 \%$ & $76.9 \%$ & \\
\hline \multirow[b]{2}{*}{ Hemoptysis } & Present & $24.3 \%$ & $75.5 \%$ & \multirow[t]{2}{*}{0.25} \\
\hline & Absent & $15.9 \%$ & $84.1 \%$ & \\
\hline \multirow[t]{2}{*}{ Confusion } & Present & $61.8 \%$ & $38,2 \%$ & \multirow[t]{2}{*}{$<0.001$} \\
\hline & Absent & $5.2 \%$ & $94.8 \%$ & \\
\hline \multirow[b]{2}{*}{$\mathrm{He}$} & Present & $8.8 \%$ & $91.2 \%$ & \multirow[t]{2}{*}{0.11} \\
\hline & absent & $7 \%$ & $79.3 \%$ & \\
\hline
\end{tabular}

The absence of cough, pleuritic chest pain, and sputum production and the presence of dyspnoea and confusion is associated with an increase in chance of death.

Table 3: Outcome and physical signs

\begin{tabular}{|c|c|c|c|c|}
\hline \multirow{2}{*}{\multicolumn{2}{|c|}{ SIGN }} & \multicolumn{2}{|c|}{ Outcome } & \multirow[t]{2}{*}{$\mathrm{P}$ value } \\
\hline & & Died & Survived & \\
\hline \multirow[t]{2}{*}{ Pulse rate } & $60-100 / \mathrm{min}$ & $6.2 \%$ & $93.6 \%$ & \multirow[b]{2}{*}{0.001} \\
\hline & $>100 /$ min & $26.7 \%$ & $73.3 \%$ & \\
\hline \multirow{2}{*}{$\begin{array}{l}\text { Systolic blood } \\
\text { pressure }\end{array}$} & $<90 \mathrm{~mm} \mathrm{Hg}$ & $70 \%$ & $30 \%$ & \multirow[b]{2}{*}{$<0.0001$} \\
\hline & $>90 \mathrm{~mm} \mathrm{Hg}$ & $10 \%$ & $90 \%$ & \\
\hline \multirow{2}{*}{$\begin{array}{l}\text { Diastolic } \\
\text { blood pressure }\end{array}$} & $<60 \mathrm{~mm} \mathrm{Hg}$ & $77.3 \%$ & $22.7 \%$ & \multirow[b]{2}{*}{$<0.001$} \\
\hline & $>60 \mathrm{~mm} \mathrm{Hg}$ & $7.8 \%$ & $92.2 \%$ & \\
\hline \multirow{3}{*}{$\begin{array}{l}\text { Respiratory } \\
\text { rate }\end{array}$} & $<16$ & 0 & $100 \%$ & \multirow{3}{*}{$<0.001$} \\
\hline & $16-30$ & 0 & $100 \%$ & \\
\hline & $>30$ & $39.7 \%$ & $60.3 \%$ & \\
\hline \multirow[t]{2}{*}{ Crepitations } & Yes & $18 \%$ & $82 \%$ & \multirow[b]{2}{*}{0.98} \\
\hline & No & $18.2 \%$ & $81.8 \%$ & \\
\hline \multirow{2}{*}{$\begin{array}{l}\text { Bronchial } \\
\text { breathing }\end{array}$} & Yes & $22 \%$ & $78 \%$ & \multirow[b]{2}{*}{0.3} \\
\hline & No & $15.4 \%$ & $84.6 \%$ & \\
\hline \multirow[t]{2}{*}{ Pleural rub } & Yes & $18.6 \%$ & $81.4 \%$ & \multirow[b]{2}{*}{0.9} \\
\hline & No & $17.8 \%$ & $82.2 \%$ & \\
\hline \multirow[t]{2}{*}{ Cyanosis } & Yes & $58.3 \%$ & $41.7 \%$ & \multirow[b]{2}{*}{$<0.001$} \\
\hline & No & $14.5 \%$ & $85.5 \%$ & \\
\hline \multirow[t]{2}{*}{ Wheezing } & Yes & $28.3 \%$ & $71.7 \%$ & \multirow[b]{2}{*}{0.007} \\
\hline & No & $11.1 \%$ & $88.9 \%$ & \\
\hline
\end{tabular}

The occurance of death in patients with tachycardia, hypotension and tachypnoea were statistically significant. Mortality rates were higher in those with cyanosis. 


\section{JMSCR Vol||07||Issue||03||Page 875-883||March}

Figure 5: Lobar involvement and outcome:

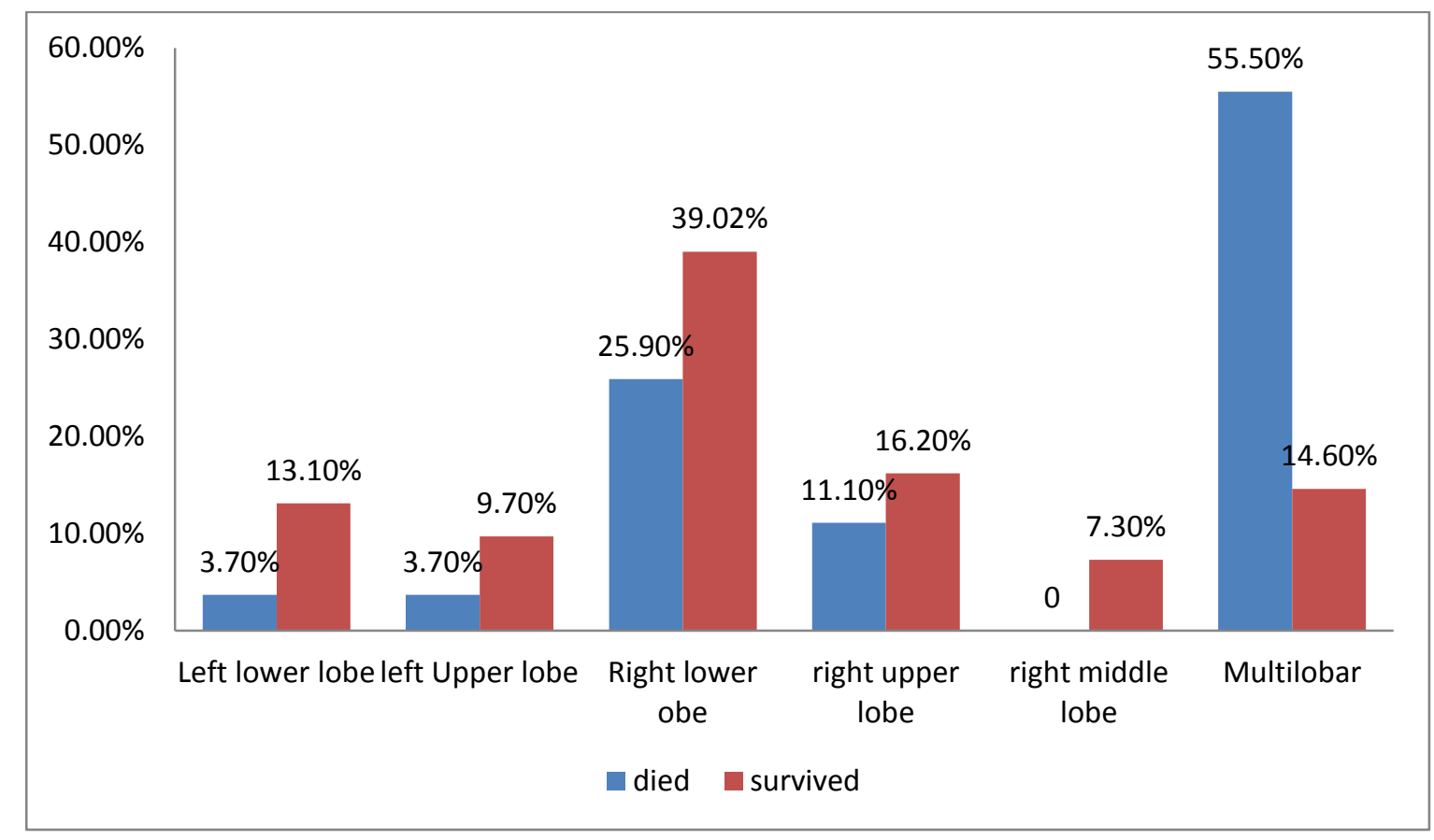

Mortality was significantly higher in those with multilobar involvement in the chest $\mathrm{X}$ ray.
The presence of diabetes mellitus was associated with increased chance of mortality and the association was statistically significant.

Table 4: CURB 65 score and outcome:

\begin{tabular}{|l|c|c|}
\hline \multirow{2}{*}{ CURB 65 SCORE } & \multicolumn{2}{|c|}{ OUTCOME } \\
\cline { 2 - 3 } & DIED & SURVIVED \\
\hline 0 & 0 & $100 \%$ \\
\hline 1 & 0 & $100 \%$ \\
\hline 2 & $6.5 \%$ & $93.5 \%$ \\
\hline 3 & $46.7 \%$ & $53.3 \%$ \\
\hline 4 & $81.2 \%$ & $18.8 \%$ \\
\hline 5 & $100 \%$ & 0 \\
\hline
\end{tabular}

Table 5: Relationship between CURB 65 score and Diabetes

\begin{tabular}{|l|c|c|}
\hline CURB 65 SCORE & DIABETICS & NON DIABETICS \\
\hline 0 & $19.15 \%$ & $80.85 \%$ \\
\hline 1 & $16.67 \%$ & $83.33 \%$ \\
\hline 2 & $32.26 \%$ & $67.74 \%$ \\
\hline 3 & $40 \%$ & $60 \%$ \\
\hline 4 & $37.5 \%$ & $62.5 \%$ \\
\hline 5 & $80 \%$ & $20 \%$ \\
\hline
\end{tabular}

Out of those with a CURB 65 score of $5,80 \%$ were diabetics.

\section{Discussion}

In our study, it was seen that community acquired pneumonia was more common in the age group $>65$ years. The incidence of community acquired pneumonia was more common in males than females. The higher incidence of Community acquired pneumonia in males may be related to the fact that males are more exposed to environmental pathogens and predisposing situations more than women. The increased incidence of community acquired pneumonia as age advances is well documented in literature and is related to multiple co morbidities and risk factors in the geriatric population. ${ }^{[1,2,3]}$ 
The most common symptoms were cough followed by fever and sputum production. However, the incidence of fever was less in diabetics when compared to non diabetics, where as the incidence of confusion and dyspnoea were more common in diabetics. This could be related to the attenuated host immune response in diabetics. Most common signs were tachypnoea and crepitations. Clinical signs in diabetics were totally different from non diabetics. Diabetics had statistically significant higher levels of serum creatinine when compared to non diabetics. This could be due to the renal dysfunction associated with diabetes itself. ${ }^{[1,4-7]}$

The most common risk factors identified were smoking and alcoholism. ${ }^{[8,9]}$

Some organism could be isolated from either the blood or the sputum in $33 \%$ of the patients. Pneumococcus was the most commonly isolated organism. It was comparable to a few other studies. $^{[10,11]}$

Mortality was significantly higher in males and in elderly. Patients with higher CURB 65 score, tachycardia, hypotension, cyanosis and multilobar involvement were associated with a higher mortality. This was comparable to a few other studies. $^{[12-14]}$

\section{References}

1. Almirall $\mathbf{J}$ et al. risk factors for community acquired pneumonia in adults: A population based case-control study. Eur Respir J 1999;13:349-355.

2. Fieldman C. Pneumonia in elderly. Med Clin North Am 2001; 85: 1441-59.

3. Ginesu F, Pirina P. Etiology and risk factors of adult pneumonia. $\mathrm{J}$ Chemotherapy 1995;7:277-285.

4. Berntsson E et al. Etiology of Community acquired pneumonia in out patients. Eur J Clin Microbiol 1986; 5: 446-47.
5. Blanquer $\mathbf{J}$ et al. Etiology of community acquired pneumonia in Valencia, Spain. Thorax 1991; 46: 508-11.

6. Dorff GJ et al. etiologies and characteristic features of pneumonia in a multidisciplinary hospital. Am J Med Sci 1973; 266: 349-58

7. Ishida $\mathrm{T}$ et al. Etiology of Community Acquired Pneumonia in hospitalized patients- A 3 year prospective study in Japan. Chest 1998; 114: 1588-93

8. Sherman CB. The health consequences of Cigarette smoking. Pulmonary Diseases. Med Clin North Am 1992; 76: 355-75

9. Almirall $\mathrm{J}$ et al. proportion of community acquired pneumonia attributable to tobacco smoking. Chest 1999;116: 375-79.

10. Wollschlager $\mathrm{C}$ et al. the contribution of blood cultures to the diagnosis and management of community acquired pneumonia. Ann Rev Resp Dis 1985;131:80

11. Pareja A et al. Etiologic study of patients with community acquired pneumonia. Chest 1992; 101: 1207-10.

12. Woodhead MA et al. Prospective study of the etiology and outcome of pneumonia in community. Lancet 19867;1: 671-74

13. Pachon J. Severe community acquired pneumonia; Etiology, prognosis and treatment. Am Rev Resp Dis 1990;142: 369-73

14. Ortquiust A et al. Etiology, outcome and prognostic factors in community acquired pneumonia requiring hospitalization. Eur Respir J 1990;3: 1105-1113. 